\title{
Efficacy of Trigger Point Injections in Patients with Lumbar Disc Hernia without Indication for Surgery
}

\author{
Bahar Dernek ${ }^{1}$, Levent Adiyeke ${ }^{2}$, Tahir Mutlu Duymus ${ }^{2}$, \\ Akın Gokcedag $^{3}$, Fatma Nur Kesiktas ${ }^{1}$, Cihan Aksoy ${ }^{4}$ \\ ${ }^{1}$ Department of Physical Medicine and Rehabilitation, Istanbul Physical Therapy and Rehabilitation Training and Research Hospital, Istanbul, Turkey \\ ${ }^{2}$ Department of Orthopaedic and Trauma, Istanbul Haydarpasa Numune Training and Research Hospital, Istanbul, Turkey \\ ${ }^{3}$ Department of Neurosurgery, Istanbul Kanuni Sultan Suleyman Training and Research Hospital, Istanbul, Turkey \\ ${ }^{4}$ Department of Physical Medicine and Rehabilitation, Istanbul University, Istanbul Faculty of Medicine, Istanbul, Turkey
}

Study Design: Prospective comparative study.

Purpose: To investigate the efficacy of gluteal trigger point (TP) injections with prilocaine in patients with lumbosacral radiculopathy complaining of gluteal pain.

Overview of Literature: TP injections can be performed using several anesthetic agents, primarily lidocaine and prilocaine. While several studies have used lidocaine, few have used prilocaine.

Methods: A total of 65 patients who presented at the polyclinic with complaints of lower back pain with lumbar disc herniation (based on physical examination and magnetic resonance imaging) and TPs in the gluteal region were included in this prospective comparative study. Group 1 comprised 30 patients who were given TP injections, a home exercise program, and oral medications, and group 2 comprised 35 patients who were only treated with a home exercise program and oral medications. The patients' demographic data, Oswestry Disability Index (ODI) scores, and Visual Analog Scale (VAS) scores were recorded, and these data were evaluated at 1- and 3-month follow-ups.

Results: The ODI and VAS scores of both groups significantly decreased initially and at the follow-up examinations, but the decreases were more marked in group 1.

Conclusions: We obtained better results with TP injections than only a home exercise program and oral medications in patients with radiculopathy and TPs in the gluteal region.

Keywords: Lumbar disc disease; Trigger point; Injection

\section{Introduction}

Lumbar disc herniation (LDH) is one of the most common causes of nerve root pain and results from the displacement of the nucleus pulposus inside the vertebral canal. It may also manifest as lumbosacral radiculopathy due to pressure on the spinal nerve roots [1]. This condition presents with dermatomal pain due to compression of the nerve root and weakness and paresis of the muscle groups and can be diagnosed with a positive straight leg raise (Lasègue) test [2]. Several studies have shown that trigger points (TPs) are common in patients with radicu-

Received Jun 15, 2017; Revised Jul 26, 2017; Accepted Aug 17, 2017

Corresponding author: Tahir Mutlu Duymus

Department of Orthopaedics, Haydarpada Numune Training and Research Hospital, 34160 Uskudar, Istanbul, Turkey

Tel: +90-0532-354-2534, Fax: +90-216-336-0565, E-mail: dr.tahirmutlu@gmail.com 
lopathy. The presence of TP-related pain in radiculopathy, in addition to peripheral neuropathy, is a major factor of symptom aggravation [3]. TPs are irritable spots in the skeletal muscle and may manifest as palpable nodules [4]. They are common sources of regional neuromusculoskeletal pain that are widely accepted by clinicians and researchers [5]. Simons et al. [6] defined TPs as painful foci in a taut band in the skeletal muscle. These foci can be active or latent; active TPs cause spontaneous pain and motor symptoms with nerve stimulation, whereas latent TPs do not cause painful symptoms. In addition, active TPs have shown the presence of chemical mediators, such as bradykinin and serotonin [7]. Pharmacological agents, manual and physical therapy, dry needling, TP injection, and botulinum toxin injections have been widely used for the treatment of TP; however, the most important step is treating the main cause of its pathogenesis [8]. TP injections are primarily performed using lidocaine or prilocaine, and while several studies have used lidocaine, few have used prilocaine.

Therefore, we investigated the efficacy of gluteal TP injections using prilocaine in patients with lumbosacral radiculopathy and pain in the gluteal region.

\section{Materials and Methods}

\section{Subject}

The present study initially evaluated data from 275 patients who were diagnosed with LDH based on clinical examination and magnetic resonance imaging (MRI) between November 2013 and March 2014. The study included 65 patients with LDH with or without spinal canal stenosis of $20 \%-30 \%$ on lumbar MRI or TPs associated with canal stenosis. The patients with LDH comprised the main study group, and some of these patients had accompanying spinal stenosis. A problem for patients is that it is nearly impossible to create a specific group excluding spinal stenosis. In addition, some patients have stenosis outside the limits of the accepted stenotic value $[3,4]$. We expected that spinal stenosis was accompanied by findings of disc and nerve root pressure. Three clinicians in the Department of Neurosurgery evaluated all the patients and their images and reached a consensus on all decisions regarding medical and physical therapy. Patients with concomitant conditions, such as sciatalgia, piriformis syndrome, previous surgery in the gluteal region, metastatic carcinoma, or a history of using a prosthesis compromising hip biomechanics, were excluded from the study.

The patients were divided into two groups. Patients in group 1 were given injection therapy, a home exercise program, and oral nonsteroidal anti-inflammatory agents, and those in group 2 received the home exercise program and oral medications only.

In patients given injection therapy, TPs were detected with patients in the prone position using the flat palpation technique in which the taut band and TPs were localized in the superolateral gluteal region and compressed between the thumb and index finger and against the underlying bone and soft tissue [9]. The diagnostic criteria for a TP include the presence of a hypersensitive spot and patient recognition of the elicited pain as it is being felt, the presence of a taut band, and the presence of a local twitch response and jump sign, although the presence of this sign is not required for diagnosis [4]. The presence of two TPs within $3 \mathrm{~cm}$ of each other was unacceptable, and the most appropriate spot for the injection was identified as the TP. The presence of a maximum of three TPs in the gluteal region was considered appropriate for injection. After positively identifying a TP, the pain was scored on a Visual Analog Scale (VAS). One TP injection was performed in 30 patients consenting to injection therapy. A sterile 21-gauge needle attached to a $10-\mathrm{mL}$ syringe containing $5 \mathrm{~mL}$ of prilocaine and $5 \mathrm{~mL}$ of normal saline was used for each patient. With the patient in the prone position, approximately $3 \mathrm{~mL}$ of the sterile mixture was injected at the painful TP in the gluteal region using the technique suggested by Simons et al. [6], whereby the syringe is held with the fingers of the dominant hand, the TP is held between the index and middle fingers of the non-dominant hand, and the needle is inserted into the muscle at a $90^{\circ}$ angle.

Each patient was also given a home exercise program and an oral nonsteroidal anti-inflammatory agent. Patients were instructed to perform the exercises, which included postural training, muscle reactivation, and correction of flexibility and strength deficits, and the patients progressed to 4-6 weeks of functional exercises. Following recovery, the patients underwent a follow-up exercise program that included protective exercises for 2-3 days a week [10]. Oral medications included a nonsteroidal anti-inflammatory drug (etodolac, $400 \mathrm{mg}$ twice/day), a muscle relaxant (thiocolchicoside, $8 \mathrm{mg}$ twice/day), and an anti-inflammatory gel (ibuprofen gel, 3 times/day for 
10 days). Demographic data, Oswestry Disability Index (ODI) scores, and VAS scores were recorded for each patient, and all patients were evaluated 1 and 3 months after instituting these measures.

Pain severity was evaluated on a 10 -mm VAS ranging from 0 (no pain) to 10 (the worst pain imaginable). Function was evaluated using the Turkish ODI consisting of 10 items: pain intensity, personal care, lifting, sitting, walking, standing, sleeping, social life, travel, and degree of pain. Greater the total score, greater was the disability. The validity and reliability of the Turkish ODI have been evaluated previously [11].

\section{Ethics and consent to participate}

The study received ethical commity approval from Kanuni Sultan Suleyman Trainig and Research Hospital Clinical Research Ethics Committee (approval no., KAEK/2/10).

\section{Statistics}

Descriptive statistics are presented as mean, standard deviation, median, minimum, maximum, frequency, and ratio. The Kolmogorov-Smirnov test was used to measure the distribution of variables. Quantitative independent data were analyzed using the independent sample $t$-test and Mann-Whitney $U$-test, and dependent data were analyzed using the Wilcoxon test. The chi-square test was used to analyze the qualitative independent data. Statistical analyses were performed using IBM SPSS Statistics ver. 22.0 software (IBM Corp., Armonk, NY, USA).

\section{Results}

No significant differences were observed in age, sex, or baseline VAS score between the case and control groups $(p>0.005)$ (Table 1). The VAS scores at 1 and 3 months were significantly $(p<0.05)$ lower in the case versus the control group and significantly $(p<0.05)$ lower than baseline values in both groups (Table 1, Fig. 1). There were no significant differences $(p>0.005)$ in baseline ODI scores between groups, and the ODI scores at 1 and 3 months were significantly $(p<0.05)$ lower in the case than control groups and significantly $(p<0.05)$ lower than the baseline values in both groups (Table 1, Fig. 2).

\section{Discussion}

Low back pain (LBP) is a common problem that is treated by both primary care and specialty physicians. While its etiology includes several factors, LBP is usually associated with muscular components. Identifying the cause of LBP

Table 1. Comparison of the pre- and post-injection VAS and ODI scores of the two groups

\begin{tabular}{|c|c|c|c|c|c|c|c|}
\hline \multirow{2}{*}{ Variable } & \multicolumn{3}{|c|}{ Case group } & \multicolumn{3}{|c|}{ Control group } & \multirow{2}{*}{$p$-value } \\
\hline & Value & Median & $p$-value ${ }^{\text {a) }}$ & Value & Median & $p$-value ${ }^{\text {a) }}$ & \\
\hline Age (yr) & $44.5 \pm 9.9$ & 45.0 & & $46.2 \pm 11.0$ & 45.0 & & $0.533^{b)}$ \\
\hline Sex & & & & & & & $0.104^{c)}$ \\
\hline Female & 27 (90.0) & & & $26(74.3)$ & & & \\
\hline Male & $3(10.0)$ & & & $9(25.7)$ & & & \\
\hline \multicolumn{8}{|l|}{ VAS } \\
\hline Baseline & $8.4 \pm 0.5$ & 8.0 & & $8.2 \pm 0.4$ & 8.0 & & $0.138^{d)}$ \\
\hline Month 1 & $2.9 \pm 1.4$ & 2.0 & $0.000^{\mathrm{e})}$ & $6.7 \pm 1.4$ & 7.0 & $0.000^{\mathrm{e})}$ & $0.000^{d)}$ \\
\hline Month 3 & $2.9 \pm 1.4$ & 2.0 & $0.000^{\mathrm{e})}$ & $6.7 \pm 1.4$ & 7.0 & $0.000^{\mathrm{e})}$ & $0.000^{d)}$ \\
\hline \multicolumn{8}{|l|}{ ODI } \\
\hline Baseline & $84.6 \pm 8.3$ & 90.0 & & $88.2 \pm 3.8$ & 90.0 & & $0.091^{\mathrm{d})}$ \\
\hline Month 1 & $40.2 \pm 17.8$ & 38.0 & $0.000^{\mathrm{e})}$ & $78.3 \pm 7.5$ & 80.0 & $0.000^{\mathrm{e})}$ & $0.000^{d)}$ \\
\hline Month 3 & $40.9 \pm 17.8$ & 40.0 & $0.000^{\mathrm{e})}$ & $80.0 \pm 0.0$ & 80.0 & $0.000^{e)}$ & $0.000^{d)}$ \\
\hline
\end{tabular}

Values are presented as mean \pm standard deviation or number (\%), unless otherwise stated. Significant statistically values were written in bold type. VAS, Visual Analog Scale; ODI, Oswestry Disability Index.

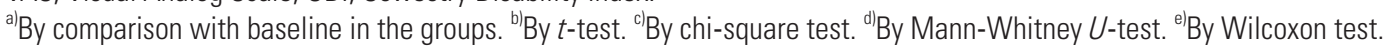




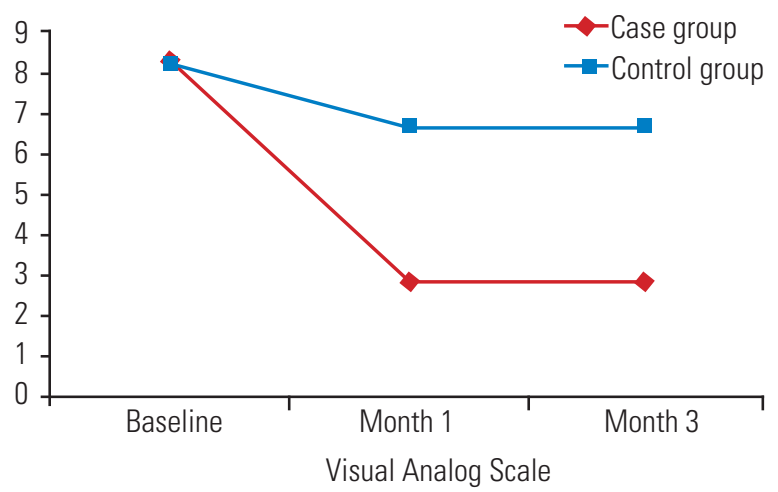

Fig. 1. Visual Analog Scale scores of the two groups.

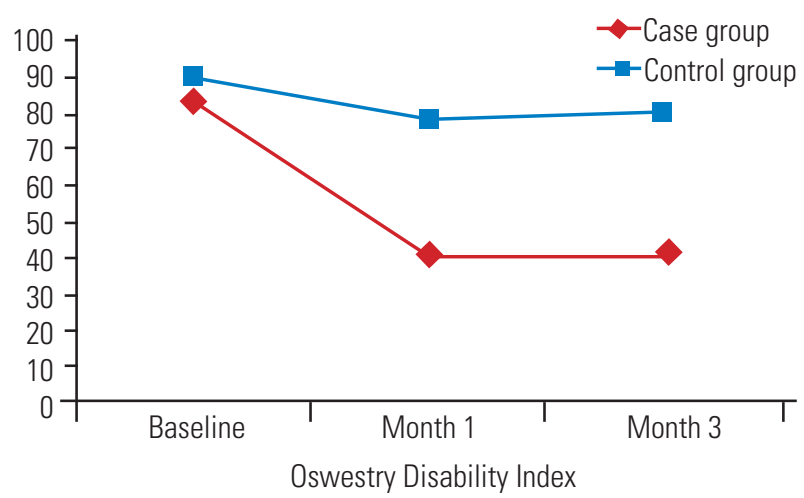

Fig. 2. Oswestry Disability Index scores of the two groups.

in clinical practice is challenging because there are usually several causes. Intervertebral disc herniation, one of the most common causes of LBP, affects the nerve roots, leading to lumbosacral radiculopathy [12], which is often accompanied by lumbar and gluteal local TPs. Patients with TPs experience additional pain and discomfort, which can complicate radiculopathy treatment [13].

In a study of 207 patients with gluteal TPs, Adelmanesh et al. [12] found that $74.6 \%$ had TPs ipsilateral to the radiculopathy. Active TPs located in the gluteus minimus muscle can mimic sciatica during the chronic phase of radiculopathy [12]. The location of the TPs is often not anatomically clear. Nevertheless, Akamatsu et al. [14] identified TPs as entry points of the spinal accessory nerve into the trapezius muscle and tendon in a cadaver study. TPs may result from trauma to or overload of specific muscle groups. Repetitive strain injuries can cause the formation of chronic TPs. Instead of the generic term "muscle pain," terms such as local soft tissue pain, local fibromyalgia, and idiopathic myalgia may be used. TPs can be palpated as taut bands in specific locations [15]; the palpation of these tender spots causes a local twitch response, which activates alpha motor neurons. In our study, a local twitch response was obtained at the active TP foci. A detailed history and physical examination are essential for the diagnosis of a TP due to limited diagnostic laboratory tests [16].

Iglesias-González et al. [17] evaluated 42 patients with nonspecific LBP and revealed that TPs in the lumbar area and hip muscles are particularly important sources of nonspecific LBP. They also demonstrated that patients with nonspecific LBP have a greater disability and worse sleep quality than individuals without a TP [17]. TP injection is preferred when conservative methods fail [9]. Various conservative approaches can be used in the management of TP, the most common of which are dry needling and local anesthetic administration. The gauge of the needle used for TP injection can also affect treatment success. While previous studies used 21-, 25-, and 27-gauge needles [18], we preferred to use a green 21-gauge needle in the present study.

The injection site should be cleaned with an antiseptic agent and sterilized prior to performing the injection [19]. We used Betadine to clean the site, with the patient in a prone position, using the technique of Simons et al. [6] for the injection, which we believed to be more effective [20]. In vitro studies have revealed that local anesthetics reduce the release of free oxygen radicals from polymorphonuclear leukocytes (PMNLs) [21]. In vivo studies have shown that local anesthetic administration inhibits adhesion and leukocyte migration [22,23]. Local anesthetics have also been found to decrease the release of histamine from mast cells and leukotriene B4 from PMNLs as well as the release of interleukin-1 (IL-1) [24]. Due to their short half-lives and lower local irritant effects, lidocaine and prilocaine are the most commonly used local anesthetics for injection [9]. Hameroff et al. [25] administered bupivacaine $0.5 \%$, etidocaine $1 \%$, or physiologic saline to the neck and lumbar muscles and observed a greater pain decrease with the use of local anesthetics compared with saline, although no difference was noted between the two anesthetics. Frost [26] treated patients with acute lumbar pain with either mepivacaine or saline and observed no difference after 2 weeks.

In the present study, patients undergoing medical therapy and an exercise program comprised the control group. The group receiving TP injections had significantly reduced pain and improved functional status compared 
with the controls. The different results obtained by various studies may be due to the differences in the gauge of the needle or active ingredient used as well as the method of application. Any failure to precisely localize the TP and injection of a spot adjacent to the TP may also yield unsatisfactory results. We believe that the mechanism of action and features of the anesthetic are also important determinants of TP injection success. Yuan et al. [27] showed that lidocaine inhibits lipopolysaccharide-related inflammatory mediator release from microglia and reported that the mechanism of action involves the blockage of the p38 mitogen-activated protein kinase and nuclear factor-kappa $B$ signaling pathways. Lidocaine has anti-inflammatory effects on monocytes, macrophages, and neutrophils as well as on LPS, thereby inhibiting nitric oxide, prostaglandin $\mathrm{E} 2$, tumor necrosis factor- $\alpha$, IL- $1 \beta$, and monocyte chemotactic protein-1 [28]. Given that molecules such as IL-1 are often present in the vicinity of TPs, lidocaine reduces the secondary pain due to the TP via both neurological and biochemical mechanisms. The effectiveness of various procedures, such as injections in the epidural space, facet joints, and locally sensitive TPs as well as nerve blocks, has been discussed in large database collection trials that question the efficacy of injection therapy in patients with posterior back pain [29]. Statements on the efficacy of multiple injections and various nerve blocks in the literature compared with such nonspecific studies have shown high heterogeneity [19,25].

Although few studies have used prilocaine, we prefer its use for TP injection. We found that it was effective for the treatment of TPs, and its mechanism of action may be similar to the biochemical processes involving lidocaine. Further molecular studies on the exact biochemical mechanisms of prilocaine are warranted.

\section{Conclusions}

Our study showed that patients with radiculopathy, which was possibly due to secondary TPs in the gluteal region, have favorable results with TP injection. We suggest that TP injection be part of the treatment of lumbosacral radiculopathy in selected patients.

\section{Conflict of Interest}

No potential conflict of interest relevant to this article was reported.

\section{Acknowledgments}

We thank the administrative and research nurse teams of the Physical Therapy and Rehabilitation Clinic, Istanbul Kanuni Sultan Suleyman Training and Research Hospital.

\section{References}

1. Guo W, Zhao P, Zhou W, et al. Correlation studies between MRI and the symptom scores of patients with LDH before and after manipulative therapy. Zhongguo Gu Shang 2010;23:17-9.

2. Bratt JM, Franzi LM, Linderholm AL, O’Roark EM, Kenyon NJ, Last JA. Arginase inhibition in airways from normal and nitric oxide synthase 2-knockout mice exposed to ovalbumin. Toxicol Appl Pharmacol 2010;242:1-8.

3. Sari H, Akarirmak U, Uludag M. Active myofascial trigger points might be more frequent in patients with cervical radiculopathy. Eur J Phys Rehabil Med 2012;48:237-44.

4. Travell J, Simons D. General issues. In: Travell J, Simons D, editors. Myofascial pain and dysfunction: the trigger point manual: vol. 2, the lower extremities. Baltimore (MD): Lippincott Williams and Wilkins; 1992. p.8-22.

5. Tough EA, White AR, Richards S, Campbell J. Variability of criteria used to diagnose myofascial trigger point pain syndrome: evidence from a review of the literature. Clin J Pain 2007;23:278-86.

6. Simons DG, Travell JG, Simons LS. Myofascial pain and dysfunction: the trigger point manual. 2nd ed. Baltimore (MD): Lippincott Williams \& Wilkins; 1999.

7. Shah JP, Phillips TM, Danoff JV, Gerber LH. An in vivo microanalytical technique for measuring the local biochemical milieu of human skeletal muscle. J Appl Physiol (1985) 2005;99:1977-84.

8. Narvani AA, Tsiridis E, Kendall S, Chaudhuri R, Thomas P. A preliminary report on prevalence of acetabular labrum tears in sports patients with groin pain. Knee Surg Sports Traumatol Arthrosc 2003;11:403-8.

9. Alvarez DJ, Rockwell PG. Trigger points: diagnosis and management. Am Fam Physician 2002;65:65360.

10. Kennedy DJ, Noh MY. The role of core stabilization 
in lumbosacral radiculopathy. Phys Med Rehabil Clin N Am 2011;22:91-103.

11. Yakut E, Duger T, Oksuz C, et al. Validation of the Turkish version of the Oswestry Disability Index for patients with low back pain. Spine (Phila Pa 1976) 2004;29:581-5.

12. Adelmanesh F, Jalali A, Jazayeri Shooshtari SM, Raissi GR, Ketabchi SM, Shir Y. Is there an association between lumbosacral radiculopathy and painful gluteal trigger points?: a cross-sectional study. Am J Phys Med Rehabil 2015;94:784-91.

13. Cannon DE, Dillingham TR, Miao H, Andary MT, Pezzin LE. Musculoskeletal disorders in referrals for suspected lumbosacral radiculopathy. Am J Phys Med Rehabil 2007;86:957-61.

14. Akamatsu FE, Ayres BR, Saleh SO, et al. Trigger points: an anatomical substratum. Biomed Res Int 2015;2015:623287.

15. Ramsook RR, Malanga GA. Myofascial low back pain. Curr Pain Headache Rep 2012;16:423-32.

16. Partanen JV, Ojala TA, Arokoski JP. Myofascial syndrome and pain: a neurophysiological approach. Pathophysiology 2010;17:19-28.

17. Iglesias-Gonzalez JJ, Munoz-Garcia MT, Rodriguesde-Souza DP, Alburquerque-Sendin F, Fernandezde-Las-Penas C. Myofascial trigger points, pain, disability, and sleep quality in patients with chronic nonspecific low back pain. Pain Med 2013;14:196470.

18. Garvey TA, Marks MR, Wiesel SW. A prospective, randomized, double-blind evaluation of trigger-point injection therapy for low-back pain. Spine (Phila Pa 1976) 1989;14:962-4.

19. Kamanli A, Kaya A, Ardicoglu O, Ozgocmen S, Zengin FO, Bayik Y. Comparison of lidocaine injection, botulinum toxin injection, and dry needling to trigger points in myofascial pain syndrome. Rheumatol Int 2005;25:604-11.
20. McPartland JM. Travell trigger points: molecular and osteopathic perspectives. J Am Osteopath Assoc 2004;104:244-9.

21. Cederholm I, Briheim G, Rutberg H, Dahlgren C. Effects of five amino-amide local anaesthetic agents on human polymorphonuclear leukocytes measured by chemiluminescence. Acta Anaesthesiol Scand 1994;38:704-10.

22. Eriksson AS, Sinclair R, Cassuto J, Thomsen P. Influence of lidocaine on leukocyte function in the surgical wound. Anesthesiology 1992;77:74-8.

23. MacGregor RR, Thorner RE, Wright DM. Lidocaine inhibits granulocyte adherence and prevents granulocyte delivery to inflammatory sites. Blood 1980;56:203-9.

24. Sinclair R, Eriksson AS, Gretzer C, Cassuto J, Thomsen $P$. Inhibitory effects of amide local anaesthetics on stimulus-induced human leukocyte metabolic activation, LTB4 release and IL-1 secretion in vitro. Acta Anaesthesiol Scand 1993;37:159-65.

25. Hameroff SR, Crago BR, Blitt CD, Womble J, Kanel J. Comparison of bupivacaine, etidocaine, and saline for trigger-point therapy. Anesth Analg 1981;60:7525.

26. Frost A. Diclofenac versus lidocaine as injection therapy in myofascial pain. Scand J Rheumatol 1986;15:153-6.

27. Yuan T, Li Z, Li X, Yu G, Wang N, Yang X. Lidocaine attenuates lipopolysaccharide-induced inflammatory responses in microglia. J Surg Res 2014;192:150-62.

28. Tasi WC, Petersen-Jones SM, Huang PY, Lin CT. The neuroprotective effects of lidocaine and methylprednisolone in a rat model of retinal ischemia-reperfusion injury. J Vet Med Sci 2012;74:307-13.

29. Staal JB, de Bie R, de Vet HC, Hildebrandt J, Nelemans P. Injection therapy for subacute and chronic low-back pain. Cochrane Database Syst Rev 2008;(3):CD001824. 